\title{
Influence of the temperature on the fracture energy of a methacrylate adhesive for mining applications
}

\author{
J. Moller ${ }^{1}$, R. Hunter ${ }^{*}$ (D, J. Molina ${ }^{1}$, A. Vizán², J. Peréz ${ }^{2}$ and L. F. M. da Silva ${ }^{3}$
}

${ }^{*}$ Correspondence: renato.hunter@ufrontera.cl

${ }^{1}$ Departamento de Ingeniería Mecánica Universidad de La Frontera, Av. Francisco Salazar, 01145 Temuco, Chile Full list of author information is available at the end of the article

\begin{abstract}
The effects of the increase in temperature are of great importance when evaluating the strength of an adhesive. Some processes in mining, such as copper electro-wining, produce thermal changes that modify the working conditions of equipment and structures; these elements are exposed to temperatures that can reach up to $80^{\circ} \mathrm{C}$. The study presented here aims to determine the behavior, under fracture of mode I type, of a two-component adhesive regularly used to join pieces in acid mist extraction systems. For this purpose, specimens for a double cantilever beam test were produced and tested in an Instron tensile machine, which includes an environmental chamber to control the test temperature; each lot of specimens was tested at 20,50 and $80^{\circ} \mathrm{C}$ respectively, at a speed of $1 \mathrm{~mm} / \mathrm{min}$. From the results obtained, it is possible to appreciate that the adhesive at $50{ }^{\circ} \mathrm{C}$ decreased its strength by $14 \%$ with respect to those at the reference temperature of $20^{\circ} \mathrm{C}$. The same tendency was observed in the specimens tested at $80^{\circ} \mathrm{C}$, in which there was a pronounced reduction in strength quantified by $26 \%$. Moreover, deformation in the adhesive grew with the increase in temperature, acquiring greater plasticity and modifying its cohesive properties.
\end{abstract}

Keywords: Double cantilever beam (DCB), Adhesive joint, Experimental testing

\section{Background}

The addition of new material technologies in mining, energy, construction and aerospace industry, among others, have requested the concentration of several researches to guide and enhance the implementation of the same. Due to the development of these new materials, a number of researches have been developed to improve the materials adhesion, which traditionally use bolted or riveted joints, whose solutions may bring some disadvantages such as stress concentration. Structural adhesives are an alternative that seeks to avoid these problems. Adhesive joints have strength and stiffness properties superior to mechanically-fastened joints since they evenly distribute the resulting load avoiding stress concentrations [1,2]. These joints also provide other benefits, such as high fatigue strength, the possibility of maintaining the integrity of the substrates, no corrosion and minimum difference due to thermal expansion of the adhesive [3].

The knowledge of mechanical properties and fracture modes of an adhesive allows us to define failure mechanisms that may occur in specific load conditions and

(c) 2015 Moller et al. This article is distributed under the terms of the Creative Commons Attribution 4.0 International License (http:// creativecommons.org/licenses/by/4.0/), which permits unrestricted use, distribution, and reproduction in any medium, provided you give appropriate credit to the original author(s) and the source, provide a link to the Creative Commons license, and indicate if changes were made. 
environmental degradation. Experimental tests and numerical models provide us the information needed to optimize the selection and use of adhesives, and provides the foundation to implement possible improvements on their joint properties and/or configurations. In this sense, many researchers have studied the mechanical characterization of adhesives through Double Cantilever Beam (DCB) test, End Notched Flexure (ENF) test, Impact test, Single Lap Joint test (SLJ), among others. Saldanha et al. has mechanically characterized an adhesive that combines the properties of an epoxy and polyurethane adhesive. Experimental tests were performed to measure the stress properties, shear properties, fracture and thermal properties [4].

Regarding the Critical fracture toughness in mode I $\left(G_{I c}\right)$, double cantilever beam test is the most appropriate to calculate this parameter [5]. Estimating critical fracture energy is based on Linear-Elastic Fracture Mechanics (LEFM), requiring for its calculation a continuous measurement of the crack length in the DCB test. In order to calculate the $G_{I c}$, several methods have been developed. The Compliance Calibration Methods $(\mathrm{CCM})$, based on the Irwin-Kies equation [6], requiring the calculation of the compliance $(C)$ relative to the crack length during crack growth. The Corrected Beam Theory (CBT), that includes the effects of crack tip rotation and deflection [7]. Finally, in the Compliance-Based Beam Method (CBBM), is not necessary to measure the crack length, since using the crack equivalent concept this measurement is irrelevant depending only on the specimen's compliance during the test $[8,9]$. In this sense, Campilho et al., using the CBBM method, has found an increasing linear trend of the critical fracture energy as thickness increases [10]. Similar studies conducted by Banea et al. and Marzi et al. determined the same trend, concluding that the fracture energy increases by the increase of thickness, because the adhesive has the ability to generate increased plastic flow areas before the fracture $[11,12]$. Campilho et al. studied the influence of adherend thickness on the measured value of $G_{I c}$ of a ductile adhesive through DCB tests. Regardless of the data reduction methods, a growing trend of $\mathrm{G}_{\mathrm{IC}}$ regarding the thickness has been found, suggesting that the $G_{I C}$ is not a material parameter, but it is a parameter dependent on the geometry used [13]. Moreover, in thin-layer adhesive joints, cracks are forced to follow the defined path through the middle area, since in general the adhesive is weaker and more adaptable than the substrates, which usually causes a cohesive failure of the adhesive [14].

The effects of the increasing temperature are very important when evaluating the strength of an adhesive. Some processes in the mining industry, such as electro-winning process, produce thermal changes that modify the working conditions of equipment and structures. Such variations are related to the shrinkage, thermal expansion coefficients and the mechanical properties modification of the adhesives used [15].

Regarding to researches concerning the determination of toughness of stress fracture in adhesive thin-layers, these are concentrated in experiments at room temperature. However, some studies focus on the analysis of structural adhesives subjected to high and low temperatures. Banea et al. evaluated the effect of high temperature in mode I of an epoxy adhesive through DCB tests. To define the adhesive performance and predict the $P-\delta$ curve of the adhesive depending on the temperature; a Cohesive Zone Model $(\mathrm{CZM})$ was used expressing damage propagation by the bilinear traction-separation law [16]. Furthermore, Banea et al. has studied the fracture toughness in mode I for RTV 
silicone adhesives at high temperature $\left(200{ }^{\circ} \mathrm{C}\right)$, showing that the fracture toughness and the traction-separation law exhibit a temperature dependence [17]. Melcher at al. identified a significant reduction on fracture toughness at $-196{ }^{\circ} \mathrm{C}$ using carbon fiber adherents and an epoxy adhesive (AF-191M) [18]. Carlberger et al. has identified that the fracture energy in the epoxy adhesive XW1044-3 is affected significantly at temperatures between -40 and $80{ }^{\circ} \mathrm{C}$ [19]. Furthermore, the combined effect of test speed and temperature on the tensile properties of a high-temperature epoxy adhesive have been studied [20] Tensile tests were performed at three different speeds and various temperatures (Room Temperature (RT), 100, 125 and $150{ }^{\circ} \mathrm{C}$ ), noting that with increasing temperature, the adhesive becomes ductile, resulting in a higher deformation to breakage; the maximum tensile stress decreased linearly with temperature, while increasing logarithmically with the speed test. Recently, Banea et al. investigated the performance of a polyurethane adhesive structurally modified with Thermally Expandable Particles (TEP) at different temperature ranges, performing tensile tests to get the tensile properties of the modified and unmodified adhesive, as well as DCB tests to evaluate strength to mode I crack propagation [21].

In this work, the double cantilever beam test is analyzed in order to evaluate the influence of the temperature on the adhesive bicomponent Methacrylate Plexus MA310, about mode I fracture toughness.

\section{Experimental procedure Materials \\ Adhesive}

The methacrylate Plexus MA310 adhesive (ITW Plexus, Chicago, USA) has been selected to develop the study, since it is one of the most widely used adhesives in the manufacture of equipment for the extraction of acid mist produced by the copper cathode electro-winning process. Plexus MA310 is a two-part methacrylate adhesive designed for structural bonding of thermoplastic, metal and composite assemblies. Combined at a 1:1 ratio, MA310 has a working time of $15 \mathrm{~min}$ and achieves approximately $75 \%$ of ultimate strength in $35 \mathrm{~min}$ at room temperature $\left(23^{\circ} \mathrm{C}\right)$. The operating temperature of the adhesive is between -55 and $121{ }^{\circ} \mathrm{C}$ and the gap filling are established between 0.6 and $4 \mathrm{~mm}$ [22].

A key parameter in the study of the joints is the glass transition temperature $(\mathrm{Tg})$ of the adhesive. To determine the glass transition temperature of the adhesive Plexus MA310 an equipment whose functioning is based on the method proposed by Zhang et al. [23] was used. A Tg was determined for each sample (three specimens were tested), thereby achieving an average value of $\mathrm{Tg}$ equal to $125^{\circ} \mathrm{C}$ for the adhesive Plexus MA310.

\section{Substrates}

The adherends were made of high-strength SAE 1045 steel to prevent plastic deformation during testing. The mechanical properties of the adherends are shown in Table 1. 
Table 1 SAE 1045 steel mechanical properties

\begin{tabular}{ll}
\hline Young's modulus, $E[\mathrm{GPa}]$ & 200 \\
Yield strength, $\sigma[\mathrm{MPa}]$ & 600 \\
Ultimate tensile strength [MPa] & 930 \\
Shear modulus, G [MPa] & 85 \\
Poisson coefficient, $v$ & 0.3 \\
\hline
\end{tabular}

Tests

Bulk tensile test

For the mechanical characterization of the adhesive, an adhesive plate of $300 \times 300 \times 3 \mathrm{~mm}$ thick has been manufactured, using two hard plates impregnated with a release agent and spacers calibrated to get uniform adhesive thickness. The adhesive plate cured for $24 \mathrm{~h}$. The geometry of the specimens required for tensile test was machined on a CNC machine, according to the specifications of ASTM D-638 standard.

The bulk tensile test was developed in an INSTRON universal test machine model 3363 with a capacity of $50 \mathrm{kN}$ (Norwood, Massachusetts, USA). The tensile test was developed at room temperature considering a constant displacement speed of $1 \mathrm{~mm} /$ min. The Poisson ratio are obtained from the study realized by Read et al. [24]. By the other side, the shear modulus has been determined by the equation $=\frac{E}{2(1+v)}$, where $\mathrm{G}$ is the shear modulus, $\mathrm{E}$ is the Elastic modulus and $v$ is Poisson Ratio. An extensometer was used to measure the specimen displacement. Five specimens were tested to validate the mechanical properties described in the Table 2.

\section{Double cantilever beam test}

The geometric features of the DCB specimens are illustrated in Fig. 1. A total of 15 samples were manufactured for the tests at different temperatures (RT, 50 and $80{ }^{\circ} \mathrm{C}$ ). In order to prevent possible adhesive failure in the joint interface, it is very important the preparation of the adhesive interface of the adherend, since there are aspects that significantly affect the strength. A pretreatment may increase the joint durability under adverse environmental conditions, since in case of metal adherents provide a degree of protection against corrosion preventing metal wetting and oxidation [25]. There are mechanical and chemical pretreatments that introduce changes in surface topography. The process for surface treatment of adherends was performed according to ASTM D2651 Standard, which consists of a metal etching using a nitric-phosphoric acid solution, which generates a surface porosity and completely removes the oxidation and impurities. Subsequently, the metal is washed with distilled water and dried immediately. To end the treatment, the surface is cleaned with acetone to remove any residue.

Table 2 Plexus MA310 mechanical properties at room temperature

\begin{tabular}{ll}
\hline Young's modulus, E [MPa] & 1860 \\
Ultimate tensile strength [MPa] & 30 \\
Shear modulus, G [MPa] $]^{\mathrm{a}}$ & 665 \\
Poisson coefficient, $\nu$ & 0.38 \\
\hline a Theoretical data &
\end{tabular}




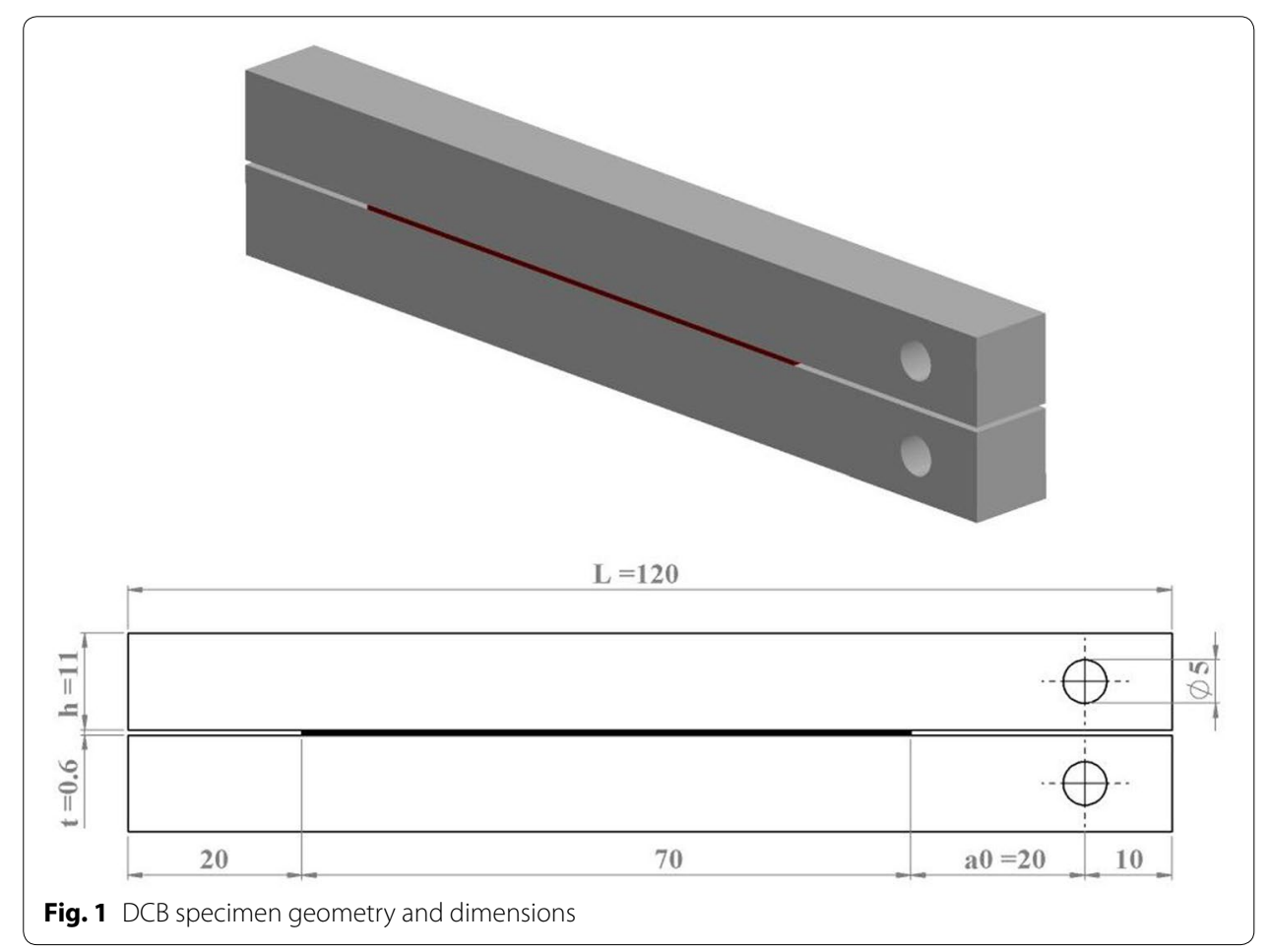

In order to maintain constant the adhesive thickness $0.6 \mathrm{~mm}$ (minimum thickness recommended by the manufacturer) between substrates, metal spacers were placed (Fig. 2). To create the pre-crack a spacer with knife-type sharp edge was used, which allowed to induce a stress concentration point in the middle plane of the edge of the adhesive layer.

After positioning the separators, the adhesive was applied through an injection gun with a mix nozzle to make a homogeneous mixture of components. The cure of the specimens was conducted at a room temperature of $20{ }^{\circ} \mathrm{C}$ for $24 \mathrm{~h}$. After that period, the spacers sheets were removed before testing each sample.

\section{DCB test procedure}

To perform the DCB test, a universal testing machine Instron Model 3363 with a capacity of $50 \mathrm{kN}$ (Norwood, Massachusetts, USA) was used. Tests were developed at a speed of $1 \mathrm{~mm} / \mathrm{min}$. For the DCB tests at RT, 50 and $80^{\circ} \mathrm{C}$, an environmental chamber Instron model 3119-606 with a temperature range of -70 to $350^{\circ} \mathrm{C}$ (Norwood, Massachusetts, USA) was used (Fig. 3 ). The $P-\delta$ curve was recorded during testing. Before starting each test, a time of $10 \mathrm{~min}$ was considered to achieve thermal equilibrium of the system. It is important to highlight that the experimental DCB data are obtained without pre-load.

\section{DCB data analysis}

Tests for characterizing the fracture under tensile load have been widely documented and studied in the literature. The most common data reduction methods to determine $G_{I c}$ derived from the principles of linear-elastic fracture mechanics; do not include the Fracture Process Zone (FPZ) in the analysis and they can be inaccurate $G_{I c}$ evaluation. One of the most practical method to assess the $G_{I c}$, Compliance Based Beam Method 

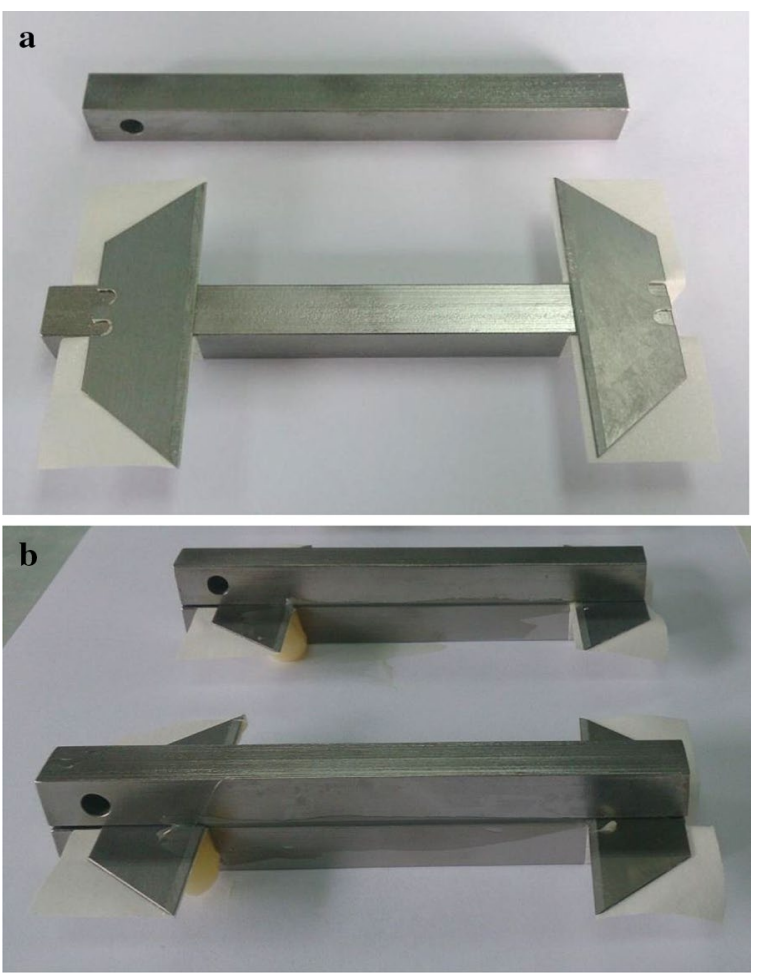

Fig. 2 a Spacers with the adherend, $\mathbf{b}$ DCB bonded joint

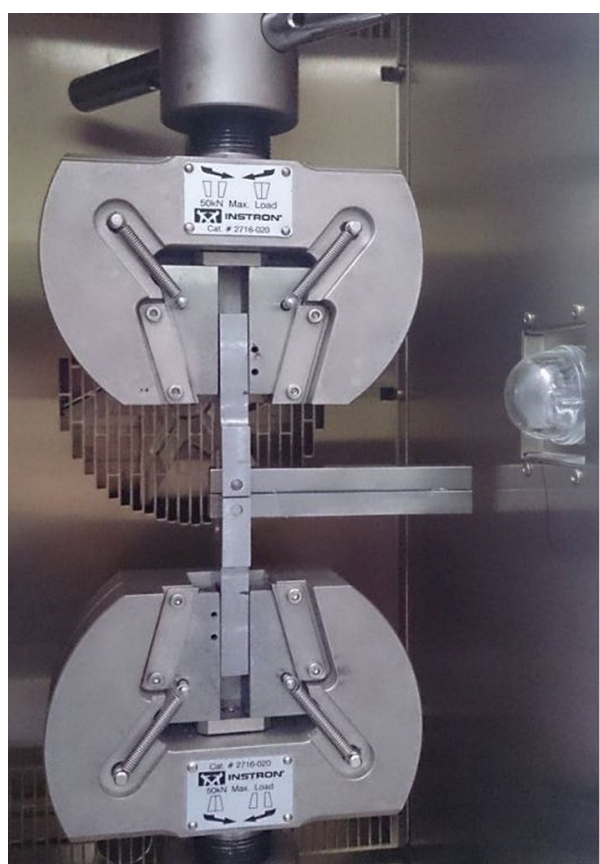

Fig. 3 DCB specimen and environmental chamber 
(CBBM), has been proposed by Moura et al. [26]. This data reduction technique is based on the equivalent crack concept, depending only on the compliance $C=\delta / P$ for the test, where $P$ is applied load and $\delta$ is the displacement. For greater accuracy of the method, it is necessary to consider a corrected $E_{f}$ flexural modulus, us which takes into account all phenomenon that influence the $P-\delta$ curve. The $E_{f}$ flexural modulus can be obtain from Eq. (1)

$$
E_{f}=\left(C_{0}-\frac{12\left(a_{0}+|\Delta|\right)}{5 B h G_{13}}\right)^{-1} \frac{8\left(a_{0}+|\Delta|\right)^{3}}{B h^{3}}
$$

where $\Delta$ is the crack rotation correction on the initial crack length $a_{0}, h$ and $B$ are thickness and width respectively, $G_{13}$ is shear modulus and $C_{0}$ is initial compliance. The concept of equivalent crack $\left(\mathrm{a}_{\mathrm{eq}}\right)$ considers the FPZ which starts in the front section of the crack as a result of the multiple micro-cracks of the nucleation through the adhesive thickness and the plastification [26]. Using this method it is not necessary to measure the crack length during the " $\mathrm{a}_{\mathrm{eq}}$ " propagation and the equivalent crack length is used instead of real one [8].

$$
G_{I C}=\frac{6 P^{2}}{B^{2} h}\left(\frac{2 a_{e q}^{2}}{h^{2} E_{f}}+\frac{1}{5 G_{13}}\right)
$$

$G_{I c}$ is obtained through Eq. 2, where $a_{e q}=a+|\Delta|+\Delta a_{F P Z}$ is the equivalent crack length which is obtained through the experimental compliance and includes the effect of FPZ; $a$ is the real crack length, it is the crack rotation correction of the initial crack length, obtained by linear regression of $C^{1 / 3}=f\left(a_{0}\right)$ and $\triangle a_{F P Z}$ is the correction induced by the presence of FPZ and $G$ is the shear modulus of adherends.

\section{DCB FE simulation}

\section{Modelling conditions}

The FE software ABAQUS ${ }^{\circledR}$ was considered for this study to evaluate the strength and the damage propagation in the adhesive during the DCB test. With the data obtained experimentally, it was possible to implement a two-dimensional exponential formulation cohesive zone model, since it was the model with the best approximation to the results of DCB test. Adherends were considered with isotropic elastic properties and the adhesive was represented with an exponential cohesive model. A structured mesh was constructed by adjusting the size of the elements according to the adhesive thickness, allowing an accurate capture of stress variations. A refined mesh was used in the damage propagation region, considering a length of $0.3 \mathrm{~mm}$ for the elements in the horizontal direction (Fig. 4). To simulate the joint, CPE4R four-node plane strain elements and $\mathrm{COH} 2 \mathrm{D} 4$ four-node cohesive elements were considered, assigned to the adherends and adhesive respectively [27]. In order to simulate the test condition, a restriction of zero displacement was applied in the " $X$ " and " $Y$ " axis in the area of the lower pin and a zero displacement in the " $\mathrm{X}$ " axis of the upper pin. The pulling movement of the machine was represented by a vertical displacement equal to $1.4 \mathrm{~mm}$ (depending on experiment) applied on the upper pin. 


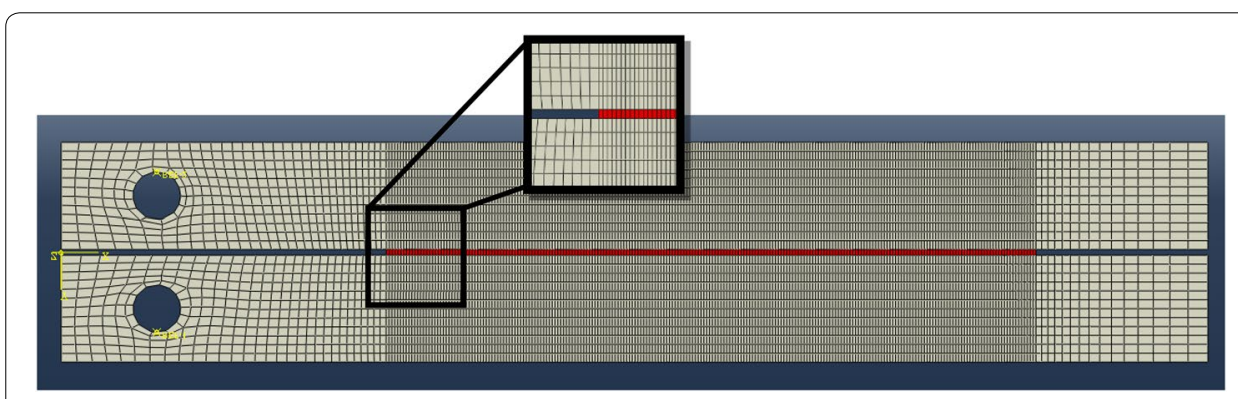

Fig. 4 Mesh of the DCB specimen

\section{Cohesive zone modelling}

The cohesive zone models predict the behavior of an adhesive by determining its maximum resisting load before damage initiates and growth due to a pre-existing local crack in the material. The CZM are based on the relationship between stress and and relative displacement connecting counterparts nodes of cohesive elements to simulate the elastic behavior up to $t_{n}^{0}$ (tension) or $t_{s}^{0}$ (shear) and posterior gradual degradation of the material until its failure. In this work the exponential cohesive law (Fig. 5) was implemented to numerically obtain the P- $\delta$ curve by using the ABAQUS ${ }^{\circledR}$ program.

$G_{n}$ y $G_{s}$ represent the area under the curve of the cohesive law in tension or shear. The definition of maximum relative displacements $\delta_{n}$ and $\delta_{s}$ (tension or shear), is done by equalizing $G_{n}=G_{n}^{C}$ for tension or $G_{s}=G_{s}^{C}$ for shear. Traction separation law defined for CZM assumes an initial linear elastic behavior, followed by exponential evolution of damage. The elasticity is defined by an elastic constitutive matrix relating the stresses and strains across the interface.

$$
t=\left\{\begin{array}{l}
t_{n} \\
t_{s}
\end{array}\right\}=\left[\begin{array}{ll}
K_{n n} & K_{n s} \\
K_{n s} & K_{n n}
\end{array}\right]\left\{\begin{array}{l}
\varepsilon_{n} \\
\varepsilon_{s}
\end{array}\right\}=K \varepsilon
$$

The matrix contains stiffness parameters of the adhesive layer; an adequate approximation for thin adhesive layers is defined by por $K_{n n}=E, K_{s s}=G, K_{n s}=0$. Initiation of damage was assessed by the criterion of square nominal stress.

\section{Results}

\section{Experimental results}

Representative experimental $P-\delta$ curves of the DCB specimens at each temperature are showed in Fig. 6. It is possible to observe a significant decrease in the maximum load as

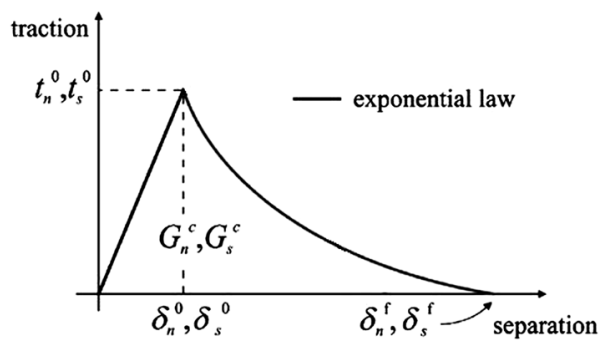

Fig. 5 Traction-separation law with exponential softening law available in ABAQUS ${ }^{\circledR}$ 


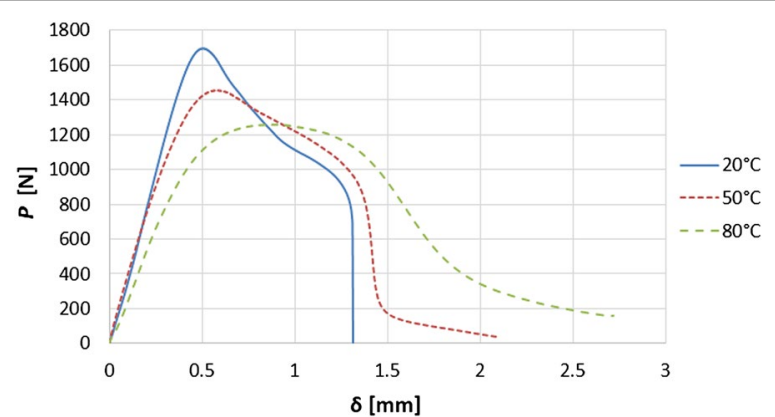

Fig. 6 Experimental P- $\delta$ curves of the DCB specimens as a function of temperature

the temperature increases. Considering the maximum load of each scenario, it is possible to observe a decrease of $14 \%$ at $50{ }^{\circ} \mathrm{C}$ with respect to the load at room temperature. The same trend was observed in the specimens tested at $80^{\circ} \mathrm{C}$, where the maximum load decrease a $26 \%$ regarding the maximum load at room temperature. For the displacement case, it can be seen that temperature increase produces increases in the displacement.

The critical energy fracture in mode I was determined using the method presented in "DCB FE simulation". The example of the experimental R curve is illustrated for RT, 50 and $80{ }^{\circ} \mathrm{C}$, Fig. 7. In this case, it is noted that once the failure occurs, there is an area that tends to keep constant the $G_{I C}$, instead of having an undisturbed drop.

Figure 8 showed the effect of temperature on the $G_{I C}$. According to the results, a similarity in the magnitude of the $G_{I c}$ for the specimens tested at RT and $50{ }^{\circ} \mathrm{C}$ is produced; at such temperatures the adhesive is still away from the glass transition temperature ( $\mathrm{Tg}$ equal to $125^{\circ} \mathrm{C}$ ), so that it maintains its mechanical properties without decreasing its cohesive characteristics.

At $80{ }^{\circ} \mathrm{C}$, a marked increase in $G_{I c}$ of approximately $30 \%$ can be observed. This can be explained by the fact that, as the temperature increases, near to the adhesive $\mathrm{Tg}$, the strength decreases but the ductility increases giving an additional plastic deformation at the crack tip, hence an increase in toughness.

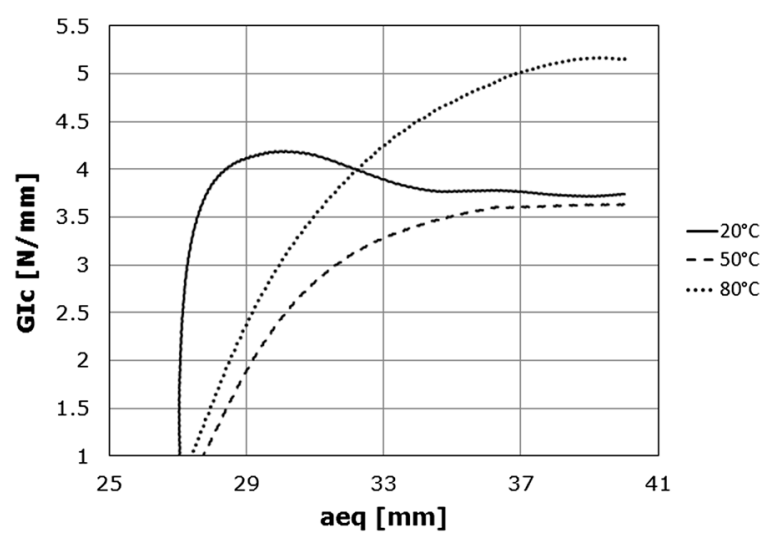

Fig. 7 Evolution of $G_{k c}$ with $a_{\text {eq }}$ for DCB test to $R T, 50$ and $80^{\circ} \mathrm{C}$ 


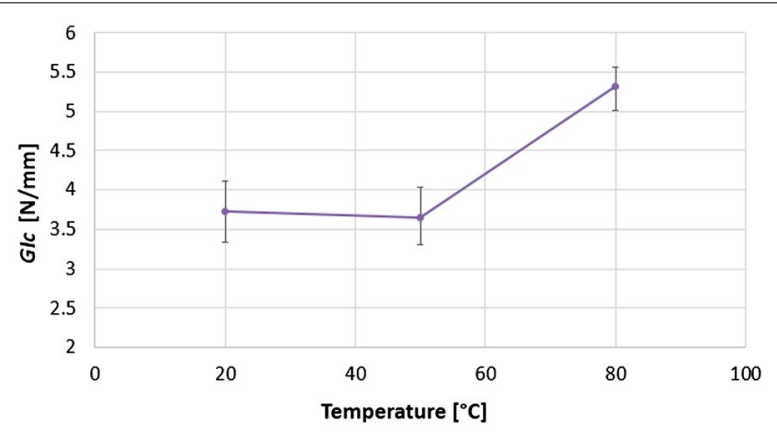

Fig. $8 G_{l c}$ as a function of temperature

In Fig. 9, the predominant failure of the DCB specimens can be appreciated. In observing failures, a similarity in the type of cohesive failure presented in the specimens tested at $\mathrm{RT}$ and $50{ }^{\circ} \mathrm{C}$ can be verified. Specifically, there exists a minimum variation in the relief between these tested samples (Fig. 9a, b) due to low plasticity generated at these temperatures. However, for the failure condition displayed in the samples at $80{ }^{\circ} \mathrm{C}$ (Fig. 9c), it is possible to observe a ductile failure represented by the significant rise of reliefs due to increased plasticity generated by the high temperature, close to $\operatorname{Tg}\left(125^{\circ} \mathrm{C}\right)$.

\section{Simulation results}

Figure 10 shows the results of DCB modeling at room temperature. In this figure it is possible to graphically display the various stages of the DCB test for the characterization of the adhesive. Point A is positioned in the linear region representing the elastic deformation of the adhesive. Cohesive failure of the adhesive material starts from the peak load when modeling with finite element (type COH2D4) is done; after the maximum load starts the fracturing process, which generates a gradual decrease in load according to traction-separation law implemented in ABAQUS ${ }^{\circledR}$. Accuracy in predicting forces is determined by the selected type of CZM; the best experimental curve fit was obtained with exponential CZM. Using this model of damage it was possible to determine the

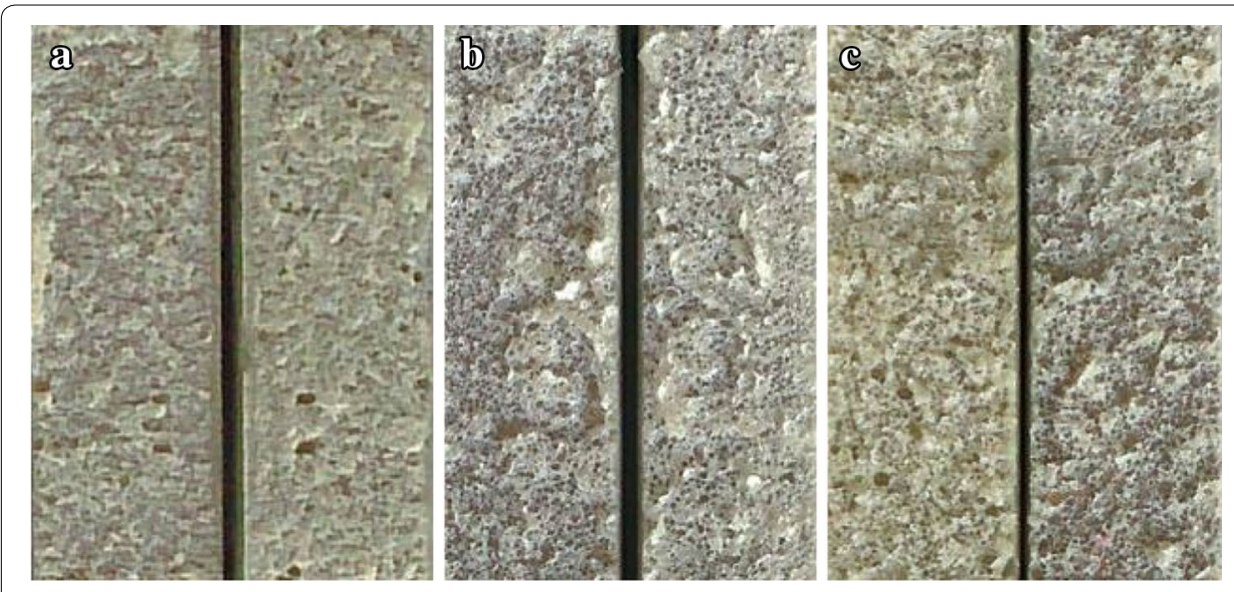

Fig. 9 Cohesive failure a RT, b Temp. $50^{\circ} \mathrm{C}$, $\mathbf{c} T e m p .80^{\circ} \mathrm{C}$ 


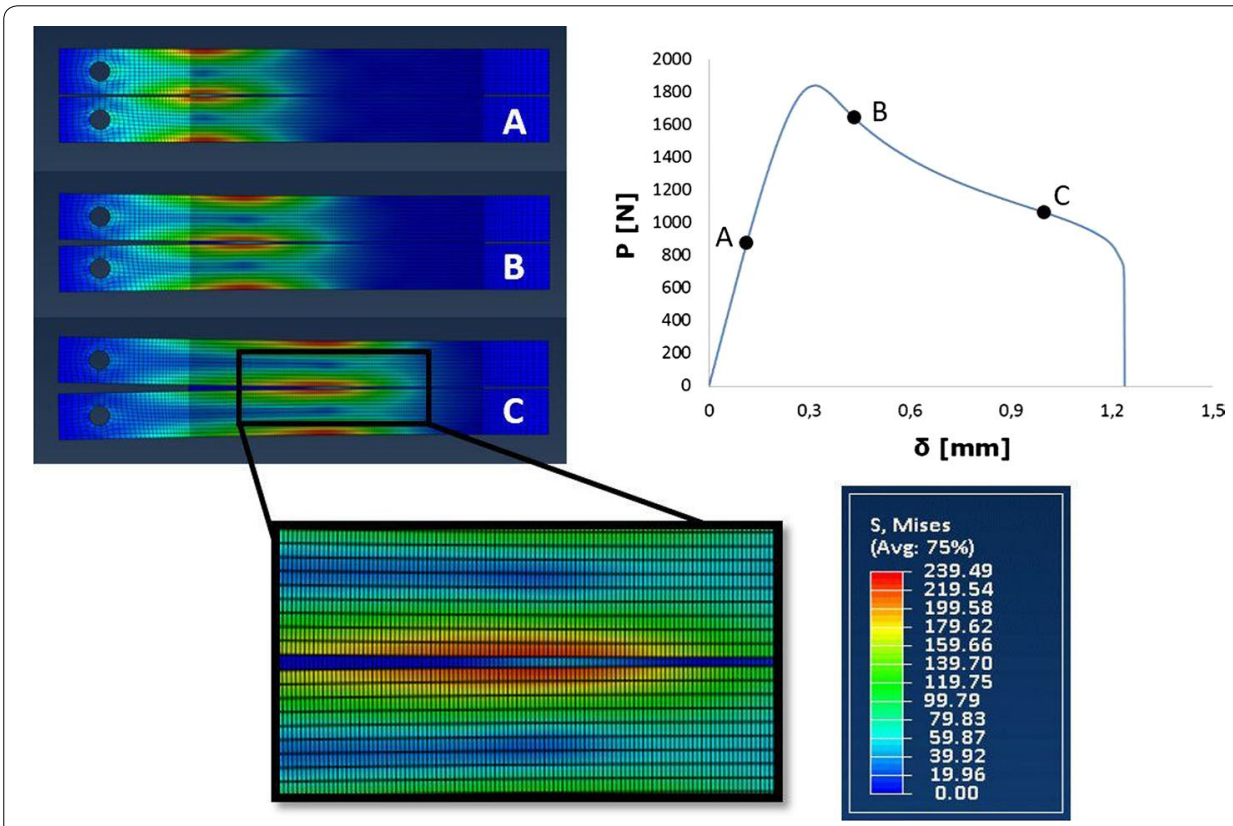

Fig. 10 Stress distribution with a CZM. A Elastic zone. B Initial fracture propagation. C Final fracture propagation

crack propagation, which depends directly on the fracture energy obtained experimentally. Points B and C are located in the area of damage evolution, associated each to a crack length. Regarding the distribution and magnitude of stresses, it was observed that for the adherent material they didn't exceed the yield strength corresponding to the steel used for the preparation of specimens. Besides, there was a symmetrical distribution of these stresses for both adherents along the entire fracturing process.

At room temperature and under the test conditions presented, stability is obtained in the fracture process that allows to simulate the adhesive performance more precisely. Therefore, the trend of $P-\delta$ curve in the model is similar to the experimental results (Fig. 11). It is important to highlight the difference in the elastic zone, previous to the crack initiation. This difference it probably produced by the components tolerance of the universal testing machine during the experimental test of the DCB.

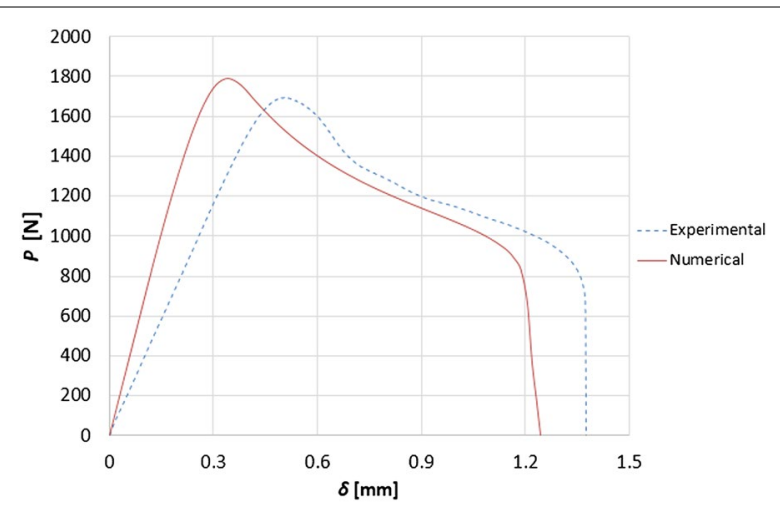

Fig. 11 Experimental and numerical P- $\delta$ curves of DCB specimen at RT 


\section{Conclusions}

The main purpose of this study was to evaluate the influence of temperature on a structural adhesive (methacrylate Plexus MA310) used in the manufacture of systems for capturing acid mist for the mining industry. An experimental test was developed by the DCB tests in order to determine the $P-\delta$ curves that show the adhesive behavior. A simulation by FE was also developed, which includes a Cohesive Zone Model that allowed to predict the stress distribution and damage propagation in the adhesive, being validated by the $P-\delta$ curve at room temperature. For the results obtained, the following conclusions can be drawn:

- The gradual temperature increase in the adhesive causes a decrease of the maximum load, while displacement increases progressively.

- Considering fracture energy with respect to the $\mathrm{a}_{\mathrm{ep}}$, at $\mathrm{RT}$, it can be seen that after the failure is produced, there is an area in which the $G_{I c}$ is kept constant.

- Regarding the $G_{I C}$ it is seen a slight decrease at $50^{\circ}$ regarding the RT; however, by increasing the temperature to $80^{\circ} \mathrm{C}$, there is a significantly increase of the $G_{I c}$, which may be explained due to increased ductility given by an additional plastic deformation at the crack tip.

- The effect generated by the change in the thermal conditions caused the adhesive to modify its cohesive properties, directly influencing the strength under peel loads.

- Regarding to the DCB simulation, the cohesive zone model have been used to determine the behavior and predict the P- $\delta$ curve. The simulation results shows that the stress levels are inside to the range of steel and adhesive properties and also shows a good stress symmetry. The difference between the experimental and numerical $\mathrm{P}-\delta$ curves it is produced by a gap in the displacement of the experimental P- $\delta$ curve. This gap occurs due to the adjustment of the jaws during the test execution. Respect to this gap, the application of a pre-load previous to the DCB test, minimize the excessive displacement produced by the jaws during the experimental test.

Authors' contributions

JM carried out some parts of the draft preparation and in the analysis data. RH carried out the draft and the experimental results. JMM participated in the specimen preparation of the single lap joint and the mechanical tensile test. AV participated in the draft manuscript and in the critical analysis of the experimental data. JP participated in the analysis of the experimental and statistical analysis. LS participated in the analysis data and helped to the draft manuscript. All authors have read and approval the final manuscript.

\section{Author details}

${ }^{1}$ Departamento de Ingeniería Mecánica, Universidad de La Frontera, Av. Francisco Salazar, 01145 Temuco, Chile.

${ }^{2}$ Departamento de Ingeniería Mecánica y Fabricación, E.T.S. Ingenieros Industriales, Universidad Politécnica de Madrid, José Gutiérrez Abascal 2, 28006 Madrid, Spain. ${ }^{3}$ Departamento de Engenharia Mecânica, Faculdade de Engenharia da, Universidade do Porto, Rua Dr. Roberto Frias, s/n, 4200-465 Porto, Portugal.

\section{Acknowledgements}

The authors acknowledge the funding of projects FONDECYT 1131058 and DIUFRO DI08-0030 for the development of this work.

\section{Competing interests}

The authors declare that they have no competing interests. 


\section{References}

1. Baldan A. Adhesively-bonded joints in metallic alloys, polymers and composite materials: mechanical and environmental durability performance. J Mater Sci. 2004;39:4729-97.

2. Sina Ebnesajjad. Adhesives Technology Hanbook. 2nd ed. Norwich: William Andrew Inc.; 2008.

3. Banea MD, Da Silva LFM. Adhesively bonded joints in composite materials: an overview. J Mater Design Appl. 2009;223:1-18.

4. Saldanha DFS, Canto C, Da Silva LFM, Carbas RJC, Chaves FJP, Nomur K, Ueda T. Mechanical characterization of a high elongation and high toughness epoxy adhesive. Int J Adhes Adhes. 2013;47:91-8.

5. Yoshihara $\mathrm{H}$. Simple estimation of critical stress intensity factors of wood by tests with double cantilever beam and three point end notched flexure. Holzforschung. 2007;61:182-9.

6. Kanninen MF, Popelar CH. Advanced fracture mechanics. Oxford: Oxford University Press; 1985.

7. Robinson P, Das S. Mode I DCB testing of composite laminates reinforced with z-direction pins: a simple model for the investigation of data reduction strategies. Eng Fract Mech. 2004;71:345-64.

8. De Moura MFSF, Morais JJL, Dourado N. A new data reduction scheme for mode I wood fracture characterization using the double cantilever beam test. Eng Fract Mech. 2008;75:3852-65.

9. De Moura MFSF, Gonçalves JPM, Chousal JAG, Campilho RDSG. Cohesive and continuum mixed-mode damage models applied to the simulation of the mechanical behavior of bonded joints. Int J Adhes Adhes. 2008;28:419-26

10. Campilho RDSG, De Moura DC, Banea MD, Da Silva LFM. Adhesive thickness effects of a ductile adhesive by optical measurement techniques. Int J Adhes Adhes. 2015;57:125-32.

11. Banea MD, Da Silva LFM, Campilho RDSG. The effect of adhesive thickness on the mechanical behavior of a structural polyurethane adhesive. J Adhes. 2015;91:331-46.

12. Marzi S, Biel A, Stigh U. On experimental methods to investigate the effect of layer thickness on the fracture behavior of adhesively bonded joints. Int J Adhes Adhes. 2011;31:840-50.

13. Campilho RDSG, De Moura DC, Banea MD, Da Silva LFM. Adherend thickness effect on the tensile fracture toughness of a structural adhesive using an optical data acquisition method. Int J Adhes Adhes. 2014;53:15-22.

14. Zou GP, Shahin K, Taheri F. An analytical solution for the analysis of symmetric composite adhesively bonded joints. Compos Struct. 2004;65:499-510

15. Adams RD, Mallik V. The effect of temperature on the strength of adhesively-bonded composite-aluminum joints. J Adhes. 1993:43:17-33.

16. Banea MD, De Sousa FSM, Da Silva LFM, Campilho RDSG. Effects of temperature and loading rate on the mechanical properties of a high temperature epoxy adhesive. J Adhes Sci Technol. 2011;25:2461-74.

17. Banea MD, Da Silva LFM, Campilho RDSG. Temperature dependence of the fracture toughness of adhesively bonded joints. J Adhes Sci Technol. 2010;24:2011-26.

18. Melcher RJ, Johnson WS. Mode I fracture toughness of an adhesively bonded composite-composite joint in a cryogenic environment. Compos Sci Technol. 2007;67:501-6.

19. Carlberger T, Biel A, Stigh U. Influence of temperature and strain rate on cohesive properties of a structural epoxy adhesive. Int J Fract. 2009;155:155-66.

20. Banea MD, Banea MD, Da Silva LFM, Campilho RDSG. Mode I fracture toughness of adhesively bonded joints as a function of temperature: experimental and numerical study. Int J Adhes Adhes. 2011;31:273-9.

21. Banea MD, Da Silva LFM, Carbas RJC, Campilho RDSG. Mechanical and thermal characterization of a structural polyurethane adhesive modified with thermally expandable particles. Int J Adhes Adhes. 2014;54:191-9.

22. ITW Plexus. Technical data sheet for Plexus MA310. 2015

23. Zhang $Y$, Adams RD, da Silva LFM. A rapid method for measuring the glass transition temperature using a novel dynamic mechanical analysis method. J. Adhesion. 2013;89:785-806.

24. Read BE, Dean GD, Duncan BC. Strain rate and temperature dependence of the adhesives. Prediction of High-rate data. NPL Report CMMT (A) 1999. p. 69.

25. Critchlow GW, Webb PW. Chemical conversion coatings for structural adhesive bonding of plain carbon steels. Int $J$ Adhes Adhes. 2000;20:113-22.

26. de Moura MFSF, Campilho RDSG, Gonçalves JPM. Crack equivalent concept applied to the fracture characterization of bonded joints under pure mode I loading. Compos Sci Technol. 2009;68:2224-30.

27. ABAQUS ${ }^{\circledR}$ Documentation. Abaqus Analysis User Guide. Electronic resource. 2015.

\section{Submit your manuscript to a SpringerOpen ${ }^{\circ}$ journal and benefit from:}

- Convenient online submission

- Rigorous peer review

- Immediate publication on acceptance

- Open access: articles freely available online

- High visibility within the field

- Retaining the copyright to your article

Submit your next manuscript at $\mathbf{s p r i n g e r o p e n . c o m ~}$ 